\title{
ANÁLISE COMPARATIVA DAS LEIS VIGENTES PARA A PRODUÇÃO ARTESANAL DE LEITE DE CABRA NO ESTADO DE SÃO PAULO
}

\author{
Elisângela Cristina Barroso Basilio ${ }^{1}$ \\ Mayara Gambellini Gonçalves ${ }^{2}$ \\ Vando Edesio Soares ${ }^{3}$
}

\begin{abstract}
RESUMO
A cabra tem acompanhado o homem desde os primórdios da humanidade, tendo sido o primeiro animal domesticado capaz de produzir alimentos. O principal produto da cabra é o leite, que pode ser consumido fluido ou transformado em queijos finos, manteiga, ricota, quefir, iogurte e outros. A legislação de Produção e o Beneficiamento, em Condições Artesanais, do Leite de Cabra e seus Derivados foi regulamentada pela Lei Estadual N. ${ }^{\circ} 6.482$ de 1989, sendo que no ano 2000 entrou em vigor a legislação de produtos artesanais de origem animal no Estado de São Paulo, regulamentado pela Lei N. ${ }^{\circ}$ 10.507. Este estudo objetivou comparar as legislações vigentes no Estado de São Paulo para a produção artesanal de leite de cabra e para produtos artesanais de origem animal, com a finalidade de orientar o produtor rural sobre o melhor enquadramento que sua atividade deve ter no Sistema de Inspeção do Estado de São Paulo (SISP) de acordo com o volume e a industrialização de sua produção. A Lei n. ${ }^{\circ}$ 6.482/1989 é específica para a produção artesanal de leite de cabra e seus derivados, mas limita o produtor rural a 500 litros por dia. Já a Lei n. ${ }^{\circ}$ 10.507/2000 é mais abrangente, tendo critérios de registro e fiscalização mais rigorosos. Estudos como este, com possível aplicação prática, são de suma importância para maior compreensão e entendimento do produtor e médico veterinário responsável, apresentando os itens das Leis de forma clara e concisa.
\end{abstract}

Palavras-chave: leite de cabra, produção artesanal, legislação, estado de São Paulo.

\section{COMPARATIVE ANALYSIS OF LAWS FOR THE PRODUCTION ARTESANAL GOAT'S MILK IN SÃO PAULO STATE}

\begin{abstract}
The goat has accompanied man since the dawn of humanity, it was the first domesticated animal capable of producing food. The main product is goat's milk, fluid that can be consumed or processed into fine cheeses, butter, cottage cheese, kefir, yogurt and others. The production of legislation and beneficiation in Handcrafted conditions, goat milk and its derivatives was regulated by State Law No. 6,482 of 1989, and in 2000 entered into force legislation handicraft products of animal origin in the State of São Paulo, regulated by Law No. 10,507. This study aimed to compare the laws in force in the State of São Paulo to the handmade production of goat milk and craft products of animal origin, in order to guide the farmers on the best framework that its activity should be in the Inspection System State of Sao Paulo (SISP) according to the volume and the industrialization of production. Law No. 6,482 / 1989 is specific to the production of handmade goat milk and its derivatives, but limits the

\footnotetext{
${ }^{1}$ Médica Veterinária, Mestrando Produção Animal, Universidade Camilo Castelo Branco - UNICASTELO, Descalvado, SP. Correspondência.

${ }^{2}$ Biomédica, Mestranda do Programa de Microbiologia, área Industrial e Alimentos, Universidade Estadual Júlio de Mesquita Filho - UNESP/Ibilce, São José do Rio Preto, SP.

${ }^{3}$ Prof. Titular da Universidade Camilo Castelo Branco - UNICASTELO, Descalvado, SP. Coordenador de Mestrado Profissional em Produção Animal.
}

Basilio ECB, Gonçalves MG, Soares VE. Análise comparativa das leis vigentes para a produção artesanal de leite de cabra no estado de São Paulo. Vet. e Zootec. 2017 Set.; 24(3): 554-562. 
farmers to 500 liters per day. Since Law No. 10,507 / 2000 is more comprehensive, with registration criteria and stricter supervision. Studies like this with possible practical application, are important to greater comprehension and understanding of the producer and the veterinarian responsible, presenting the items of the laws clearly and concisely.

Keywords: goat milk, craft production, legislation, state of Sao Paulo.

\title{
ANALISIS COMPARATIVO DE LEYES PARA LA PRODUCCIÓN ARTESANAL DE LECHE DE CABRA EN SAO PAULO ESTADO
}

\begin{abstract}
RESUMEN
La cabra ha acompañado al hombre desde los albores de la humanidad, fue el primer animal domesticado capaz de producir alimentos. El producto principal es la leche de cabra, el líquido que se puede consumir o transformada en quesos finos, mantequilla, requesón, el kéfir, yogur y otros. La producción de la legislación y de beneficio en condiciones artesanales, leche de cabra y sus derivados se rige por la Ley del Estado $\mathrm{N}^{\mathrm{o}} 6.482$, de 1989, y en 2000 entró en vigor la legislación productos de artesanía de origen animal en el Estado de Sao Paulo, regulada por la Ley $\mathrm{N}^{\mathrm{o}} 10.507$. Este estudio tuvo como objetivo comparar las leyes vigentes en el Estado de San Pablo a la producción artesanal de leche de cabra y de artesanía productos de origen animal, con el fin de orientar a los agricultores en el marco más adecuado que su actividad debe estar en el Sistema de Inspección Estado de Sao Paulo (SISP) de acuerdo con el volumen y la industrialización de la producción. Ley $\mathrm{N}^{\circ} 6.482$ / 1989 es específica para la producción de leche de cabra artesanal y sus derivados, pero limita los agricultores a 500 litros por día. Dado que la Ley $N^{\circ} 10.507$ / 2000 es más completo, con criterios de registro y supervisión más estricta. Estudios como éste, con una posible aplicación práctica, son extremadamente importantes para una mayor comprensión y entendimiento del productor y el veterinario responsable, la presentación de los artículos de las Leyes de manera clara y concisa.
\end{abstract}

Palabras clave: leche de cabra, de producción artesanal, legislación, Estado de Sao Paulo.

\section{INTRODUÇÃO}

A cabra tem acompanhado o homem desde os primórdios da humanidade, tendo sido o primeiro animal domesticado capaz de produzir alimentos (1). Seu principal produto é o leite, que pode ser consumido fluido ou transformado em queijos finos, manteiga, ricota, quefir, iogurte e outros.

O leite de cabra é definido na legislação brasileira como o produto oriundo da ordenha completa, ininterrupta, em condições de higiene, de animais da espécie caprina sadios, bem alimentados e descansados (2). Sua composição varia de acordo com a raça, condições ambientais, estágio da lactação, alimentação, cuidados com o animal, ciclo estral, estado de saúde, idade e quantidade de leite produzido (3).

A exploração dos caprinos para leite apresenta-se em expansão, devido ao leite ser considerado um produto de alto valor nutritivo e à capacidade dos caprinos de se adaptar a condições criatórias variáveis (4). No Brasil, a caprinocultura conta com o incentivo de ações conjuntas de governos estaduais, instituições de pesquisa e criadores, atingindo uma produção estimada de leite de 21 milhões de litros e envolve, em grande parte, empresas de pequeno porte (5). 
A produção e comercialização dos produtos artesanais de leite pode incrementar a geração de lucros nas micro e pequenas propriedades rurais. Nestas propriedades, a produção de leite de cabra e seus derivados é regulamenta por legislação especifica. O produtor deve estar ciente das exigências de cada legislação e escolher qual melhor atende suas necessidades, considerando a origem e o volume da matéria-prima e os produtos a serem comercializados.

A legislação de Produção e o Beneficiamento, em Condições Artesanais, do Leite de Cabra e seus Derivados foi regulamentada pela Lei Estadual N. ${ }^{\circ} 6.482$, de 5 de setembro de 1989 (6), sendo que no ano 2000 entrou em vigor a legislação de produtos artesanais de origem animal no Estado de São Paulo, regulamentado pela Lei N. ${ }^{\circ} 10.507$ de 01 de março de 2000 (7) sendo mais especifica com relação as instalações e equipamentos.

A Lei N. $^{\circ}$ 6.482, de 05 de setembro de 1989 dispõe sobre a Produção e o Beneficiamento, em Condições Artesanais, do Leite de Cabra e seus Derivados. Já a Lei N. ${ }^{\circ}$ 10.507 , de $1 .^{\circ}$ de março de 2000 estabelece normas para a elaboração, sob a forma artesanal, de produtos comestíveis de origem animal e sua comercialização no Estado de São Paulo e dá providências correlatas.

Considerando a existência destas Leis no Estado de São Paulo, este estudo faz uma comparação dos pontos de acordo, desacordo e complementares das Leis para produção de leite de cabra, em escala artesanal, com a finalidade de orientar o produtor rural na escolha de qual legislação solicitar registro junto ao CIPOA - Centro de Inspeção de Produtos de Origem Animal, da CDA - Coordenadoria de Defesa Agropecuária, da SAA/SP - Secretaria de Agricultura e Abastecimento de São Paulo.

\section{MATERIAIS E MÉTODOS}

Foi aplicada a este estudo uma pesquisa qualitativa, explicativa e documental, pela análise e comparação das legislações vigentes para a produção artesanal de leite de cabra e derivados, utilizando-se também artigos, leis e informações disponíveis na literatura. As Leis comparadas e discutidas neste estudo são a Lei n ${ }^{\circ} 10507 / 2000$ e Lei $n^{\circ}$ 6482/1989, que dispõe sobre a produção artesanal de leite e derivados. Seus decretos e resoluções foram citados e não especificados e discutidos.

\section{RESULTADOS E DISCUSSÃO}

O produtor, ao escolher em qual Lei adequa-se sua produção artesanal de leite de cabra e derivados deverá considerar todos os pontos abordados na Lei, desde a matéria-prima até a distribuição para comercialização.

\section{Matéria-prima}

O primeiro item considerado é a matéria-prima e quantidade desta que será utilizada. Se o objetivo do produtor rural for produção de leite integral pasteurizado de cabra, com volume inferior a 500 litros/dia, com produção de derivados e recebimento de matéria prima de terceiros, adequar-se-á na Lei n. ${ }^{\circ}$ 6.482/1989. Porém, se o objetivo do produtor rural for a produção artesanal em pequena escala de produtos lácteos, com processamento de até 300 litros de leite diários, com matéria-prima de produção própria, podendo adquiri-la de terceiros até o limite de $50 \%$ da quantidade de matéria-prima de produção própria - desde que tenha comprovação de inspeção higiênico-sanitária por órgão oficial - enquadrando-se na Lei n. ${ }^{\circ}$ $10.507 / 2000$. 
Contudo, se o objetivo do produtor for a produção de leite pasteurizado de cabra/outros em maior escala, com volume superior a 500 litros/dia, com produção de derivados e recebimento de terceiros, adequar-se-á na Lei n ${ }^{\circ}$ 8.208/1992 (8), porém, deixará de ser considerado como produção artesanal, passando a classificar-se como produção industrial.

A Lei n. ${ }^{\circ}$ 6.482/1989, em seu artigo 7, proíbe a mistura de leite de cabra com a de outras espécies para comercialização. Nas Leis 10.507 e 8.208, não consta esta informação, ausência falha, uma vez que podem ocorrer misturas. $\mathrm{O}$ artigo 33 da referida Lei, menciona ainda as fraudes, adulterações e falsificações do leite de cabra, quando estes: sofrerem adição de água e de substâncias conservantes ou estranhas à sua composição, tiver sofrido subtração de seus componentes, estiver cru e for vendido como pasteurizado e estiver exposto de forma violável. Tais características, embora estejam descritas na Lei n. $^{\circ}$ 6.482, são critérios que devem ser seguidos e considerados em qualquer tipo de produção láctea, como garantia da qualidade do produto.

\section{Rebanho}

Nos termos do art. $2^{\circ}$ da Lei $n^{\circ} 6.482 / 89$, os criadores de cabra deverão registrar seu rebanho na Secretaria de Estado da Agricultura, obrigando-os ao acompanhamento de Médico Veterinário para garantir higiene e sanidade dos animais, atualizando seus dados a cada 2 anos.

Em contrapartida, a Lei ${ }^{\circ} 10.507 / 00$ é vaga ao descrever que o controle sanitário dos rebanhos que gerem a matéria-prima para a sua produção, segue a orientação dos órgãos de defesa sanitária animal do Estado de São Paulo, sem especificá-las.

\section{Produção}

A Lei $n^{\circ}$ 6482/89 estabelece os processos de beneficiamento do leite de cabra, dividindo-os em filtração, pasteurização, refrigeração, acondicionamento e outras práticas tecnicamente aceitáveis. Todo leite de cabra, destinado ao consumo, deve ser filtrado, antes de qualquer outra operação de beneficiamento. $O$ filtro deve ser de fácil desmontagem, para completa higienização. No caso de pasteurização, permite-se o emprego de forma lenta e de curta duração, ficando proibida a repasteurização do leite de cabra, nos termos do art. 25 da Lei. Ademais, em seu art. $8^{\circ}$, afirma ser obrigatória a produção do leite de cabra em condições higiênicas, desde a fonte de origem, seja qual for a quantidade produzida e seu aproveitamento.

Já a Lei $n^{\circ} 10507 / 00$, não apresenta detalhadamente os quesitos de produção, exigindo apenas que a elaboração dos produtos seja realizada em estabelecimentos apropriados para este fim, ficando vedado o processamento em locais destinados à residência ou a outras atividades que prejudiquem o processamento de produtos comestíveis.

\section{Registro}

Dispõe a Lei $n^{\circ} 10.507 / 00$, em seu art. $9^{\circ}$, que o produtor rural processador artesanal de produtos de origem animal deverá registrar-se junto ao Centro de Inspeção de Produtos de Origem Animal (CIPOA), do Grupo de Defesa Sanitária Animal, da Coordenadoria de Defesa Agropecuária, da Secretaria de Agricultura e Abastecimento, exigindo ao produtor requisitos como: apresentação do requerimento dirigido ao CIPOA, comprovação da condição de produtor rural, atestados ou exames, a critério do CIPOA. Deste modo, o registro referente ao requerimento, terá validade de 1 ano, devendo a solicitação de renovação ser efetuada até 30 dias antes do seu vencimento. 
Outrossim, nos termos do art. 10, o produtor artesanal deverá apresentar relatório mensal com os dados de produção, em conformidade com as normas estabelecidas pelo Centro de Inspeção de Produtos de Origem Animal, bem como manter livro para registro das informações, recomendações e visitas da fiscalização, efetuadas para controle higiênicosanitário e tecnológico da produção.

Na Lei $n^{\circ}$ 6482/89 a aplicação do registro se fará na conformidade e em obediência ao previsto nas normas técnicas a serem baixadas pela Secretaria de Agricultura, cabendo, portanto, ao médico veterinário responsável tomar ciência do disposto nas normas e aplique ao registro do produtor.

\section{Comercialização}

Nos termos da Lei n. ${ }^{\circ}$ 10.507/00, o transporte e a armazenagem dos produtos deverão obedecer às condições estabelecidas em normas técnicas da Secretaria de Agricultura e Abastecimento.

Ademais, as embalagens e os rótulos dos produtos artesanais deverão conter: a) todas as informações preconizadas pelo Código de Defesa do Consumidor; b) a indicação de que é produto artesanal; c) o seu número de registro no Centro de Inspeção de Produtos de Origem Animal; d) a indicação "Serviço de Inspeção do Estado de São Paulo - SISP".

No que tange às normas referentes à comercialização do leite de cabra, a Lei ${ }^{\circ}$ 6482/89 estabelece que o leite só poderá ser enviado a estabelecimento de comercialização após a pasteurização, devidamente embalado. É proibido o emprego de substâncias químicas para conservação do referido tipo de leite.

Outrossim, o art. 34 da Lei supracitada dispõe que, só será permitida a exposição à venda do leite de cabra e seus derivados nos estabelecimentos comerciais que disponham de sistema de refrigeração exclusivo à sua conservação ou com uma seção para esse fim, condicionada às peculiaridades da tecnologia específica para cada produto.

Por fim, fica proibida a abertura da embalagem do leite de cabra para venda fracionada do produto, salvo quando destinada ao consumo imediato nas leiterias, cafés, bares e outros estabelecimentos que sirvam refeições, nos termos da Lei ${ }^{\circ}$ 6482/89. Portanto, observa-se que a Lei $\mathrm{n}^{\circ}$ 6482/89 é mais detalhada quanto às condições de comercialização comparada à Lei n. ${ }^{\circ} 10.507 / 00$. Contudo, esta especifica normas para rotulagem.

\section{Fiscalização, Inspeção Sanitária e Multas}

A Lei $n^{\circ} 6482 / 89$ é breve e concisa ao estabelecer que a propriedade rural, para efeito de aproveitamento do leite de cabra destinada a alimentação humana, será interditada quando se verificar qualquer surto de doença infecto contagiosa que justifique a medida. Apresentando-se mais específica e exigente, a Lei n. ${ }^{\circ} 10.507 / 00$, nos termos do art. $8^{\circ}$, delega a competência de fiscalização higiênico-sanitária e tecnológica dos produtos artesanais comestíveis à Coordenadoria de Defesa Agropecuária da Secretaria de Agricultura e Abastecimento. Esta Lei preconiza também a possibilidade do Estado de São Paulo, pela Secretaria de Agricultura e Abastecimento, celebrar convênios com os Municípios que disponham de estrutura técnica e laboratorial, bem como com outras pessoas jurídicas de direito público capacitadas, delegando-lhes a fiscalização prevista, visando garantir os aspectos higiênico-sanitários, tecnológicos e o controle de qualidade dos produtos.

Os infratores desta lei, de seus regulamentos e demais normas dela decorrentes, ficam sujeitos à advertência, multa, apreensão ou condenação das matérias-primas, produtos, subprodutos e derivados de origem animal adulterados ou que não apresentam condições 
higiênico-sanitárias adequadas ao fim a que se destinam; suspensão das atividades, interdição total ou parcial do estabelecimento, cancelamento do registro quando há motivo de interdição.

Ressalta-se neste item, que, conforme dispõe o art. $7^{\circ}$ da Lei $n^{\circ} 7889 / 89$, nenhum estabelecimento industrial de produtos de origem animal poderá funcionar no País sem que esteja previamente registrado no órgão competente para a fiscalização de sua atividade.

\section{Análises}

A Lei $\mathrm{n}^{\circ}$ 6482/89, estabelece, em seus artigos 28 e seguintes, que a análise do leite de cabra, seja qual for o fim a que se destine, abrangerá os caracteres organolépticos e as provas de precisão e/ou rotina. E, após as provas de rotina, para que o leite de cabra seja considerado anormal ou fora do padrão, deverá ser submetido a, pelo menos, três provas de rotina, ou uma prova de rotina e uma de precisão. Para a determinação do padrão bacteriológico e das enzimas do leite, adotar-se-ão as provas de redutase, fosfatase, peroxidase, contagem microbiana e testes de presença de coliformes, devendo ser, para o leite pasteurizado, a prova de fosfatase negativa e a peroxidase positiva.

Considera-se leite de cabra impróprio para consumo "in natura", o que não satisfaz as exigências previstas para a sua produção e, ainda, que não atenda as exigências da lei.

Outrossim, o leite de cabra para ser exposto ao consumo, deve satisfazer as exigências do leite integral.

No que tange a Lei n. ${ }^{\circ} 10.507 / 00$, estipula apenas que o Centro de Inspeção de Produtos de Origem Animal estabelecerá em regulamento, sem ônus para o produtor, as análises de rotina necessárias para cada produto processado.

\section{Comparação}

Na tabela 1, estão relacionados os itens descritos nas Leis, facilitando a visualização das exigências a sua interpretação pelo produtor.

Tabela 1. Comparação dos itens das Leis vigentes no Estado de São Paulo para produção artesanal de leite de cabra e derivados.

\begin{tabular}{|c|c|c|}
\hline ITENS & $\begin{array}{c}\text { Lei } \mathrm{N}^{\circ}{ }^{\circ} 6.482 \\
05 \text { de setembro de } 1989\end{array}$ & $\begin{array}{c}\text { Lei N. }{ }^{\circ} 10.507 \\
01 \text { de março de } 2000\end{array}$ \\
\hline DISPOSIÇÃO & $\begin{array}{c}\text { Dispõe sobre a produção e o } \\
\text { beneficiamento, em condições artesanais, } \\
\text { do leite de cabra e derivados }\end{array}$ & $\begin{array}{c}\text { Estabelece normas para a elaboração, sob } \\
\text { a forma artesanal, de produtos } \\
\text { comestíveis de origem animal }\end{array}$ \\
\hline REGULAMENTAÇÕES & Resolução SAA N. ${ }^{\circ}$ 93, de 14/10/1993 & $\begin{array}{c}\text { Decreto No } 45.164 \text {, de 5/09/2000; } \\
\text { Resolução SAA n }{ }^{\circ} 30 \text {, de 24/09/2001; } \\
\text { Resolução SAA n } 43 \text {, de 13/09/2010 }\end{array}$ \\
\hline MATÉRIA-PRIMA & $\begin{array}{l}\text { Leite de cabra de produção própria, } \\
\text { admitindo-se a utilização de matéria- } \\
\text { prima adquirida de terceiros. }\end{array}$ & $\begin{array}{l}\text { Matéria-prima de produção própria. } \\
\text { Admite-se a utilização de matéria-prima } \\
\text { adquirida de terceiros até o limite de 50\% } \\
\text { da quantidade de matéria-prima de } \\
\text { produção própria. }\end{array}$ \\
\hline QUANTIDADE & $\begin{array}{c}\text { Quantidade que pode variar até } 500 \\
\text { litros/dia e, ou, também elabore produtos } \\
\text { derivados do leite. }\end{array}$ & $\begin{array}{c}\text { Até } 300 \text { litros/dia (como matéria-prima } \\
\text { para produtos lácteos) }\end{array}$ \\
\hline
\end{tabular}




\begin{tabular}{l|c|c}
\hline PRODUTOS & $\begin{array}{c}\text { Leite de cabra integral e pasteurizado e } \\
\text { seus derivados }\end{array}$ & Produtos de origem animal \\
\hline & - Registro do rebanho na Secretaria de &
\end{tabular}

Estado da Agricultura, atualizando os dados a cada 2 anos.

REBANHO - Manutenção do estado sanitário do rebanho, com medidas profiláticas e terapêuticas.
Obrigatoriedade do controle sanitário dos rebanhos que gerem a matéria-prima para a sua produção, observando a orientação dos órgãos de defesa sanitária animal do Estado de São Paulo.
- Condições Higiênicas obrigatórias, independente da quantidade produzida e seu aproveitamento.

- Para os leites de cabra provenientes de outros criadores, é obrigatória a retirada prévia de amostras de cada criador para fins de análise individual.

- A ordenha deve ser feita diariamente com regularidade, e o leite deve ser passado por tela milimétrica,

convenientemente limpa momentos antes do uso, para outro vasilhame previamente higienizado.

- O leite de cabra só poderá ser retido na propriedade quando pasteurizado e refrigerado.
- O uso de substâncias químicas para a conservação de leite de cabra é proibido.

-O leite só poderá ser enviado a

BENEFICIAMENTO E INDUSTRIALIZAÇÃO estabelecimento de comercialização, após a pasteurização, devidamente embalado. - É proibida a repasteurização do leite de cabra.

Permite-se os processos de pasteurização lenta e de curta duração.

- Envasado em sistema automático ou semi automático.

- Embalado em sacos plásticos deverá ser fechado por instrumento próprio, e se for embalado em garrafas plásticas terá uma terminação para fechamento adaptada de maneira inviolável. As embalagens não poderão ser reaproveitadas.

Realizado mediante acondicionamento em caixas isotérmicas ou em cestas

plásticas rigorosamente higienizadas que serão transportadas ao comércio

TRANSPORTE

distribuidor por meio de veículos dotados de carroceria isotérmica.
- Elaboração dos produtos em estabelecimentos apropriados para este fim, ficando vedado o processamento em locais destinados à residência ou a outras atividades que prejudiquem $o$ processamento de produtos comestíveis. - Leite de cabra provenientes de outros criadores que tenha comprovação de inspeção higiênico-sanitária por órgão oficial.
- As instalações do estabelecimento processador artesanal de alimentos de origem animal observarão preceitos simplificados, no tocante à construção e aos equipamentos, estabelecidos em normas técnicas da Secretaria de Agricultura e Abastecimento.

O leite deverá ser pasteurizado sempre que normas higiênico-sanitárias e tecnológicas o exigirem, aceitando-se a pasteurização lenta.

As embalagens e os rótulos dos produtos artesanais deverão conter todas as informações preconizadas pelo Código de Defesa do Consumidor; a indicação de que é produto artesanal; e o seu número de registro no Centro de Inspeção de

Produtos de Origem Animal e a indicação

"Serviço de Inspeção do Estado de São Paulo - SISP".

O transporte e a armazenagem dos produtos artesanais deverão obedecer às condições estabelecidas em normas técnicas da Secretaria de Agricultura e Abastecimento.

- Características organolépticas e provas de precisão e /ou rotina, sendo submetido a, pelo menos, 3 (três) provas de rotina,

\section{O Centro de Inspeção de Produtos de Origem Animal estabelecerá em regulamento, sem ônus para o produtor,}




\begin{tabular}{|c|c|c|}
\hline & $\begin{array}{c}\text { ou } 1 \text { (uma) prova de rotina e } 1 \text { (uma) de } \\
\text { precisão. } \\
\text { - Provas de redutase, fosfatase, } \\
\text { peroxidase, contagem microbiana e testes } \\
\text { de presença de coliformes. } \\
\text { - Provas para diagnóstico de brucelose e } \\
\text { de tuberculose, são obrigatórias a cada } 6 \\
\text { meses e seus resultados encaminhados à } \\
\text { Casa de Agricultura local. }\end{array}$ & $\begin{array}{l}\text { as análises de rotina necessárias para cada } \\
\text { produto processado. }\end{array}$ \\
\hline COMERCIALIZAÇÃO & $\begin{array}{c}\text { Exposição à venda do leite de cabra e } \\
\text { seus derivados permitida nos } \\
\text { estabelecimentos comerciais que } \\
\text { disponham de sistema de frio exclusivo à } \\
\text { sua conservação ou com uma seção para } \\
\text { este fim, condicionada às peculiaridades } \\
\text { de tecnologia específica para cada } \\
\text { produto. }\end{array}$ & $\begin{array}{l}\text { Os produtos de que trata este artigo } \\
\text { poderão ser comercializados em todo o } \\
\text { Estado de São Paulo, cumpridos os } \\
\text { requisitos desta lei. }\end{array}$ \\
\hline REGISTRO & $\begin{array}{l}\text { A aplicação das disposições desta lei, se } \\
\text { fará na conformidade e em obediência ao } \\
\text { previsto nas normas técnicas a serem } \\
\text { baixadas pela Secretaria de Agricultura. }\end{array}$ & $\begin{array}{l}\text { - Registrar-se junto ao CIPOA. } \\
\text { - O registro terá validade de } 1 \text { ano, com } \\
\text { renovação até } 30 \text { (trinta) dias antes do seu } \\
\text { vencimento. } \\
\text { - Apresentação de relatório mensal com } \\
\text { os dados de produção, em conformidade } \\
\text { com as normas preconizadas pelo CIPOA, } \\
\text { bem como manter livro para registro das } \\
\text { informações, recomendações e visitas da } \\
\text { fiscalização, efetuadas para controle } \\
\text { higiênico-sanitário e tecnológico da } \\
\text { produção. } \\
\text { - Registro da sua composição e método de } \\
\text { processamento, observadas as normas } \\
\text { técnicas estabelecidas pela Secretaria de } \\
\text { Agricultura e Abastecimento. }\end{array}$ \\
\hline PENALIDADES & $\begin{array}{c}\text { - As penalidades imputadas pelo não } \\
\text { cumprimento do estabelecido nesta lei, } \\
\text { serão aquelas previstas na legislação } \\
\text { pertinente. } \\
\text { - Será interditada a propriedade rural para } \\
\text { efeito de aproveitamento do leite de cabra } \\
\text { destinada a alimentação humana, quando } \\
\text { se verificar qualquer surto de doença } \\
\text { infecto contagiosa que justifique a } \\
\text { medida. }\end{array}$ & $\begin{array}{l}\text { - Os infratores desta lei, de seus } \\
\text { regulamentos e demais normas dela } \\
\text { decorrentes, ficam sujeitos às seguintes } \\
\text { penalidades, sem prejuízo de outras } \\
\text { sanções cabíveis: advertência, multa, } \\
\text { apreensão ou condenação das matérias- } \\
\text { primas, produtos, subprodutos e derivados } \\
\text { de origem animal adulterados ou que não } \\
\text { apresentem condições higiênico-sanitárias } \\
\text { adequadas ao fim a que se destinam; } \\
\text { suspensão das atividades, interdição total } \\
\text { ou parcial do estabelecimento, } \\
\text { cancelamento do registro quando o } \\
\text { motivo da interdição prevista no inciso } \\
\text { anterior não for sanado no prazo de } 12 \\
\text { (doze) meses. }\end{array}$ \\
\hline
\end{tabular}

\section{CONCLUSÕES}

O produtor rural artesanal do Estado de São Paulo tem duas possibilidades de enquadramento em lei, considerando a origem da matéria-prima, o volume de produção e o produto acabado.

Basilio ECB, Gonçalves MG, Soares VE. Análise comparativa das leis vigentes para a produção artesanal de leite de cabra no estado de São Paulo. Vet. e Zootec. 2017 Set.; 24(3): 554-562. 
A Lei n. ${ }^{\circ}$ 6.482/1989 é específica para a produção artesanal de leite de cabra e seus derivados, sendo mais detalhada quanto aos critérios de produção, porém breve quanto aos aspectos burocráticos, além de limitar o produtor rural a 500 litros por dia. Já a Lei n. ${ }^{\circ}$ $10.507 / 2000$ é abrangente, tendo critérios de registro e fiscalização mais rigorosos. Se o produtor optar pelo aumento na produção, esta deixará de ser em escala artesanal, enquadrando-se na Lei ${ }^{\circ}{ }^{8208 / 92}$.

Ambas as Leis permitem interpretações ambíguas e apresentam critérios vagos, que permitem brechas. Critérios apresentados especificamente em uma Lei são ausentes na outra. Portanto, é cabível a elaboração de uma nova lei, adequada ao produtor contemporâneo, que contenha as especificações das duas leis, e os demais critérios pertinentes, de modo que sua apresentação seja clara e completa, de entendimento tanto do médico veterinário, quanto do produtor rural, possibilitando melhoras na produção e fiscalização do leite de cabra e de seus derivados, colaborando para o progresso da caprinocultura brasileira.

\section{REFERÊNCIAS}

1. Ribeiro AC. Estudo dos efeitos genéticos e de ambiente sobre características de importância econômica em caprinos da raça Saneen [dissertação]. Jaboticabal: Universidade Estadual Paulista; 1997.

2. Ministério da Agricultura e do Abastecimento (BR). Secretaria de Defesa Agropecuária. Regulamento técnico de produção, identidade e qualidade do leite de cabra. Brasília: Ministério da Agricultura e do Abastecimento; 2000. (Instrução normativa no 37, de 31 de outubro de 2000).

3. Alves FSF, Pinheiro RR. A importância do leite de cabra na nutrição humana [Internet]. Groaíras: Embrapa; 2005 [cited 2015 Aug 27]. Available from: http://www.capritec.com.br/artigos_embrapa020829a.htm

4. Amaral DS, Amaral DS, Moura Neto LG. Tendências de consumo de leite de cabra: enfoque para a melhoria da qualidade. Rev Verde. 2011;6(1):39-42.

5. Ministério da Agricultura, Pecuária e Abastecimento (BR). Caprinos e ovinos. Brasília: MAPA; 2015.

6. Assembléia Legislativa do Estado de São Paulo (BR). Lei $n^{\circ}$ 6.482, de 5 de Setembro de 1989. Dispõe sobre a produção e o beneficiamento, em condições artesanais, do leite de cabra e seus derivados. Diário Oficial da União. 6 Set 1989.

7. Assembléia Legislativa do Estado de São Paulo (BR). Lei $\mathrm{n}^{\circ} 10.507$, de 1 de Março de 2000. Estabelece normas para a elaboração, sob a forma artesanal, de produtos comestíveis de origem animal e sua comercialização no Estado de São Paulo e dá providências correlatas. Diário Oficial da União. 2 Mar 2000.

8. Assembléia Legislativa do Estado de São Paulo (BR). Lei n ${ }^{\circ} 8.208$, de 30 de Dezembro de 1992. Dispõe sobre a prévia inspeção sanitária dos produtos de origem animal, institui taxas e dá outras providências. Diário Oficial da União. 31 Dez 1992.

Recebido em: 03/09/2016 Aceito em: 05/07/2017 